\title{
Future of computerised electrocardiography
}

\author{
FRITS L MEIJLER, ETIENNE O ROBLES DE MEDINA, JAN C HELDER \\ From the Department of Cardiology and Central Computer Department, University Hospital, Utrecht, \\ The Netherlands
}

SUMMARY The advent of computerised electrocardiography has been of prime importance for the storage and retrieval of data, but none of the available systems is of universal application for analysis of patterns. Future needs require hierarchical systems of increasing degrees of complexity, depending on the source of requests, and there should be appropriate provision for review by cardiologists before the final report is issued.

Despite the fact that electrocardiography is one of the most important diagnostic tools at present available to clinical cardiologists, computerised electrocardiography still lacks recognition and has not achieved an essential place in clinical practice.

Computer sciences and the application of computer techniques have been helpful in providing more insight into many electrocardiographic problems. But in computerised electrocardiography emphasis has been placed on the computer rather than on electrocardiography: "Electrocardiography has been the proving ground for many of the basic concepts of medical decision making by computer". 1 Medical decision making by computer and clinical electrocardiography do not, however, necessarily have identical goals and should be carefully distinguished. At present computerised electrocardiography is still more an engineering project than a useful and applied diagnostic tool in clinical cardiology. Moreover, computerised electrocardiography has turned out to be not only the proving ground for medical decision making by computer, but also-and perhaps mainly - the playing field for the medical electronics industry. Our patients have served as testing objects for modern electrocardiographic equipment, often very sophisticated, but not very reliable in day-to-day use. This has all been at the expense of our patients and of our hospital budgets. ${ }^{2}$ Clinical cardiologists shrug their shoulders over computer electrocardiography; let us briefly consider why this is so.

Received for publication 11 December 1979

\section{State of art of electrocardiographic reading by computer}

For the clinical evaluation of automated processing of electrocardiograms ambulatory patients are used rather than the critically ill. ${ }^{3}$ Computer analysis of the electrocardiogram does not offer any help when the complexity of a particular electrocardiogram extends the intellectual skills of an experienced cardiologist.

For those patients with complex arrhythmias and/or complicated QRS patterns, computer diagnosis is not very helpful, a state of affairs which may not change within the next decade. ${ }^{4} \mathrm{Up}$ till now automated processing of electrocardiography has neither contributed to expertise in reading of clinical electrocardiograms nor to better understanding of the fundamental electrophysiological properties of the heart. In addition, computer analysis of the electrocardiogram is, in general, no more accurate than a trained electrocardiographer for routine reading of electrocardiograms of a hospital population. ${ }^{5}$ In our experience it could not compete with respect to the cost or speed of reading of electrocardiograms, provided the human reader is provided with proper organisational tools, including support facilities. ${ }^{6}$

These unfavourable judgments, however, are only valid for those hospitals that have experienced and sophisticated facilities for reading electrocardiograms. There are undoubtedly many electrocardiographic services in smaller hospitals and 
remote places without highly skilled electrocardiographers to perform their routine readings of electrocardiograms. In those places computer electrocardiography may and probably does provide better and cheaper reading of electrocardiograms."

\section{Current clinical electrocardiography}

All are aware of the contribution of electrocardiography to the diagnosis and treatment of all sorts of patients in clinical as well as in epidemiological studies, for men in outer space, for sports medicine, and other fields. Modern medicine would certainly suffer if electrocardiography were to be removed from it.

\section{INADEQUATE STORAGE AND RETRIEVAL}

FACILITIES

Of all the electrocardiograms ever made probably more than 90 per cent are neatly folded and kept in an envelope in the private file of a doctor somewhere, somehow, or in the patients' data files of hospitals. In the same envelope or file the results of physical examinations as well as the outcome of laboratory tests, often illegible, can be found. The name of the patient, his initials, his date of birth, and the date the electrocardiogram was recorded may not have been noted on the electrocardiogram; in addition, the $1 \mathrm{mV}$ calibration and the notation of the leads on the strip may be absent. Seldom is such an electrocardiogram of good technical quality, without artefacts, alternating current interference, or baseline drift caused by loosely fitted electrodes. Moreover, it is very difficult, if not impossible, to retrieve such electrocardiograms, for instance when needed for training purposes. An immeasurable amount of electrocardiographic data which could be useful for clinical or epidemiological cardiology is thus quite inaccessible and, to all intents, lost forever.

\section{LACK OF STANDARDISATION}

The worldwide application of electrocardiography is paradoxically matched by a total lack of uniformity in electrocardiography equipment and by a Babylonian confusion in electrocardiographic terminology, classification, and criteria. This causes a complete lack of any worldwide, national, or even local system for storage, retrieval, and analysis of electrocardiograms, and interferes with exchange of electrocardiographic data between doctors, hospitals, cities, and countries which is so vital for diagnosis and treatment of cardiac patients and important for epidemiological purposes.

\section{Advantages of computer-assisted electrocardiography}

Computerised electrocardiography, if it becomes a reliable and standardised method, can and will modify all these shortcomings, because computers require organisation and well-defined circumstances. Computerised electrocardiography will take care of storage, retrieval, and routine analysis of electrocardiograms. It will eliminate the recording and thus the storage of electrocardiograms of poor technical quality and of electrocardiograms without the necessary identification data of the patient. It will, one hopes, make electrocardiography technically as reliable in operation as a well-functioning telephone system. Computerised electrocardiography will force the user to organise himself to the great advantage of the patient whose electrocardiographic data will be of good technical quality and can be retrieved at will. This aspect of organisation seems to be the most important and most promising aspect of computer-assisted electrocardiography.

Why do we always emphasise the weakest aspect of computer electrocardiography-reading of electrocardiograms-while storage and retrieval barely receive any attention? Reading of electrocardiograms by computer will be helpful in handling large numbers of normal and well defined, easily recognisable abnormal electrocardiograms." If reading of electrocardiograms by computer is not available or not desirable, an adequate electrocardiographic coding system can provide consistent terminology and classification which is a prerequisite for fast data retrieval. ${ }^{7-0}$ So, even without computer analysis of the electrocardiogram, the computer can help to organise recording, storage, and retrieval of electrocardiograms. By using a coding system embedded in simple administrative computer processing, we were able inexpensively to reduce the electrocardiographer's time to avoid numerical errors and to improve standardisation of nomenclature. ${ }^{6}$

For computer interpretation of clinical electrocardiograms we have employed Pipberger's program. ${ }^{10}$ On the basis of our experience it seems that if one considers different levels of complexity of electrocardiograms and present day limited program reliability reading of electrocardiograms by computer can and should be improved.

\section{Future of computerised electrocardiography}

STANDARDISATION OF TERMINOLOGY AND CRITERIA

At the tenth Bethesda conference on optimal electrocardiography a special task force was assigned 
to consider the quality of electrocardiographic recording. Definite requirements have been outlined for technician training, record format, lead nomenclature, electrocardiographic instrumentation, functional performance, standards for transmission of electrocardiograms, and computer acquisition and technical training criteria. ${ }^{11}$ Thus the requirements for the hardware aspects of (computer-assisted) electrocardiography are well established for the future. However, only the first tentative steps have been taken by the World Health Organisation and the American College of Cardiology to reach an agreement on standardisation of terminology and interpretation. ${ }^{12}$ What has been possible for aviation should be possible for electrocardiography as well. Standardisation of terminology is one of the cornerstones of present day worldwide air traffic facilities. Why not try to reach the same agreements for electrocardiography? A task force of the World Health Organisation has just published a report on definitions of terms related to cardiac rhythm ${ }^{13}$ and a classification of cardiac arrhythmias which also may facilitate coding and analysis of electrocardiograms. ${ }^{14}$. The QRS complex and ST-T segment, however, still remain terra incognita as far as any standardisation and/or definition of terms, let alone criteria, are concerned. Computerised electrocardiography certainly will force clinicians to reach agreement on criteria and nomenclature, but we still face a long road.

So, one major aspect of future development will be a worldwide accepted terminology for interpretation and coding of electrocardiograms.

\section{ORGANISATION}

In hospitals computer-assisted electrocardiography can be integrated into a total information system. This makes it possible to combine and correlate electrocardiographic data with other clinical information such as biochemical tests, $x$-ray reports, and the like. In addition, accounting facilities that can be linked with computerised electrocardiography may prove of importance for hospital administration.

The need for larger systems may be counterbalanced by the development and application of microprocessors which can be used in the electrocardiographic trolleys themselves. Besides signal control and signal improvement, unconfirmed reports will then be produced at the bedside, while overreading and storage of the electrocardiograms will take place in a large data base eventually connected with or integrated into a larger hospital information system. Non-routine electrocardiography like ambulatory and exercise electrocardiography will profit from specialised computer applications derived from standard processing of electrocardiograms such as data reduction capacity, indefatiguability, reproducibility, and computational power.

\section{HIERARCHICAL ANALYSIS PROGRAM}

There will always be electrocardiograms so difficult and complex that computer analysis is impossible. The same holds true for human reading. Every experienced electrocardiographer will admit that sometimes, if not often, electrocardiograms defy his skills.

So, if the future is to bring us fully integrated computer systems for handling the daily load of electrocardiograms we must face the fact that the development of one sophisticated program that is able to analyse all electrocardiograms without too many mistakes within a limited time period can be compared with the pursuit of a mirage. If we accept this axiom we should stop trying to develop programs which can handle every kind of electrocardiogram including the very complex and rarethe human brain is more suited for this. If computer reading of electrocardiograms should develop into a respected and useful clinical technique, one that can also help patients with complicated electrocardiographic abnormalities, we need a realistic approach based on clinical pragmatism rather than on wishful thinking. Such an approach could be the development of hierarchical programs. This would allow for more time and money for other important aspects of computer-assisted electrocardiography, such as storage and retrieval of the tracings and numerical data.

The first program should be used for electrocardiograms drawn from epidemiological studies, general practice, and small peripheral hospitals. From these sources we may expect a large number of normal electrocardiograms. Most available computer programs will handle these well. ${ }^{34}$ The program itself should be able to identify the electrocardiograms of a level of complexity unsuitable for that program. The most important feature missing in present-day programs is a decision by the computer that its diagnostic statement about a particular electrocardiogram is unreliable or uncertain.

A second program should automatically be called into operation for more complex electrocardiograms or, for instance, for electrocardiograms coming from sources where as a rule abnormal electrocardiograms are being produced. This program should at least be able to diagnose the most common arrhythmias like normal sinus rhythm with premature complexes or atrial fibrillation or otherwise state: "undefined rhythm, 
for subsequent reading by a cardiologist”. The program should further provide a reliable QRS-ST-T analysis, and again a warning statement should the program be unable to handle the electrocardiogram. If possible, it should provide facilities for comparison with previous electrocardiograms.

The third and most sophisticated program should handle the difficult electrocardiograms from patients in coronary and postsurgical intensive care units. These electrocardiograms usually defy conventional computer analysis. Thus a special program is needed which should also perform a sophisticated rhythm analysis. ${ }^{15}$ For those electrocardiograms with the highest level of complexity which the third program cannot handle, a cardiologist is essential.

The future should therefore bring us three different programs each standing on top of the other, or a three-in-one package which, together with human assistance and reading, will provide expert reading of all electrocardiograms.

This approach will save computer time, computer memory, and last but not least, will employ the human mind for those problems it is most suited for, namely the unique ones. The present approach using one program for all electrocardiograms can be termed a failure, at least as far as its contribution to clinical cardiology is concerned.

\section{References}

1 Warner HR. First the electrocardiogram-then what? A system for decision-making by computer. Am $\mathcal{f}$ Cardiol 1978; 41: 115-8.

2 Rautaharju PM. The impact of computers on electrocardiography. Eur 7 Cardiol 1978; 8: 237-48.

3 Brohet CR, Richman HG. Clinical evaluation of automated processing of electrocardiograms by the Veterans' Administration Program (AVA 3.4). Am f Cardiol 1979; 43: 1167-74.

4 Caceres CA. Limitations of the computer in electrocardiographic interpretation. Am $\mathcal{F}$ Cardiol 1976; 38: 362-76.
5 Bourdillon PJ, Kilpatrick D. Clinicians, the Mount Sinai Program and the Veterans' Administration Program evaluated against clinico-pathological data derived independently of the electrocardiogram. Eur f Cardiol 1978; 8: 395-412.

6 Meijler FL, Robles de Medina EO, Helder JC. An automated ECG system in a large hospital: coding, storage and retrieval of tracings. G Ital Cardiol 1975; 5: 110-21.

7 Robles de Medina EO, Meijler FL. A simple numerical coding system for clinical electrocardigraphy. Eur f Cardiol 1974; 2: 67-77.

8 Bonner RE, Caceres CA, Cuddy TE, et al. Recommendations for ECG diagnostic coding. Prepared by working group diagnostic codes. Eur f Cardiol 1978; 8: 173-6.

9 Caceres CA. Electrocardiographic coding: an overview. Eur f Cardiol 1978; 8: 145-53.

10 Pipberger HV. Computer analysis of the electrocardiogram. In: Stacy RW, Waxman B, eds. Computers in biomedical research I. New York and London: Academic Press, 1965: 377-406.

11 Tenth Bethesda Conference on optimal electrocardiography. Task Force II: Quality of electrocardiographic records. Sheffield LT (Chairman). Am f Cardiol 1978; 41: 146-57.

12 Tenth Bethesda Conference on optimal electrocardiography. Task Force I. Standardization of terminology and interpretation. Surawicz B (Chairman). Am f Cardiol 1978; 41: 130-45.

13 Bernard R, Coumel P, Damato AN, et al. Definition of terms related to cardiac rhythm. WHO/ISTC Task Force. Am Heart F 1978; 95: 796-806.

14 Robles de Medina EO, Bernard R, Coumel P, et al. Classification of cardiac arrhythmias and conduction disturbances. WHO/ISFC Task Force. Am Heart $\mathcal{f}$ 1979; 98: 263-7.

15 Plokker HWM. Cardiac rhythm diagnosis by digital computer. Thesis, Free University, Amsterdam, 1978.

Requests for reprints to Professor Frits L Meijler, Department of Cardiology, University Hospital, 3500 CG Utrecht, The Netherlands. 